\title{
Review
}

Oksana Breus and Thomas Dickmeis*

\section{Genetically encoded thiol redox-sensors in the zebrafish model: lessons for embryonic development and regeneration}

https://doi.org/10.1515/hsz-2020-0269

Received July 31, 2020; accepted September 28, 2020;

published online October 15, 2020

\begin{abstract}
Important roles for reactive oxygen species (ROS) and redox signaling in embryonic development and regenerative processes are increasingly recognized. However, it is difficult to obtain information on spatiotemporal dynamics of ROS production and signaling in vivo. The zebrafish is an excellent model for in vivo bioimaging and possesses a remarkable regenerative capacity upon tissue injury. Here, we review data obtained in this model system with genetically encoded redox-sensors targeting $\mathrm{H}_{2} \mathrm{O}_{2}$ and glutathione redox potential. We describe how such observations have prompted insight into regulation and downstream effects of redox alterations during tissue differentiation, morphogenesis and regeneration. We also discuss the properties of the different sensors and their consequences for the interpretation of in vivo imaging results. Finally, we highlight open questions and additional research fields that may benefit from further application of such sensor systems in zebrafish models of development, regeneration and disease.
\end{abstract}

Keywords: embryo; glutathione; hydrogen peroxide; imaging; regeneration; zebrafish.

\section{Introduction: why zebrafish?}

The zebrafish (Danio rerio), a small sweet water fish originating from India, has received steadily growing attention

\footnotetext{
*Corresponding author: Thomas Dickmeis, Institute of Biological and Chemical Systems - Biological Information Processing, Karlsruhe Institute of Technology, Hermann-von-Helmholtz-Platz 1, D-76344 Eggenstein-Leopoldshafen, Germany, E-mail: thomas.dickmeis@kit.edu.https://orcid.org/0000-00029819-1962

Oksana Breus, Institute of Biological and Chemical Systems Biological Information Processing, Karlsruhe Institute of Technology, Hermann-von-Helmholtz-Platz 1, D-76344 Eggenstein-Leopoldshafen, Germany
}

as a model for vertebrate biology over the past 40 years (Grunwald and Eisen 2002). Initially mainly used to tackle the genetics of vertebrate development, an ever increasing number of research topics has benefited from zebrafish studies, including neurobiology (Bollmann 2019), cardiovascular research (Gut et al. 2017), endocrinology (Lohr and Hammerschmidt 2011), toxicology (Bambino and Chu 2017), behavior (Orger and de Polavieja 2017), chronobiology (Froland Steindal and Whitmore 2019), and regeneration (Marques et al. 2019). Main features for this success were the transparency of zebrafish embryos, which allows for in vivo imaging helped by a wealth of transgenic lines targeting e.g. cell behavior, neural activity and gene expression patterns (Chow and Vermot 2017; Trinh le and Fraser 2013); and the small size of both adults and embryos, allowing large-scale mutagenesis and chemical compound screens (Bambino and Chu 2017; Lam and Peterson 2019; Patton and Zon 2001) (Figure 1). Importantly, zebrafish are used to model human diseases, both to understand the molecular mechanisms of pathogenesis and to provide a system amenable to rapid preclinical testing of new drugs and treatments (Davis and Katsanis 2017; Lam and Peterson 2019).

\section{The zebrafish as a model system for embryonic development}

Embryonic development of the zebrafish is very rapid (Kimmel et al. 1995): gastrulation, which generates the three germ layers and establishes the embryonic axis, is accomplished by $10 \mathrm{~h}$ post fertilization (hpf). The subsequent somitogenesis period is characterized by the formation of mesodermal tissue blocks next to the midline. These somites will give rise to muscle tissue and skeletal elements. By $24 \mathrm{hpf}$, basic features of major organ systems such as the nervous and cardiovascular systems as well as fin folds are formed. Slightly later, the spontaneous movements of the embryo become responsive to touch and light stimuli, indicative of increasing functional integration within the 


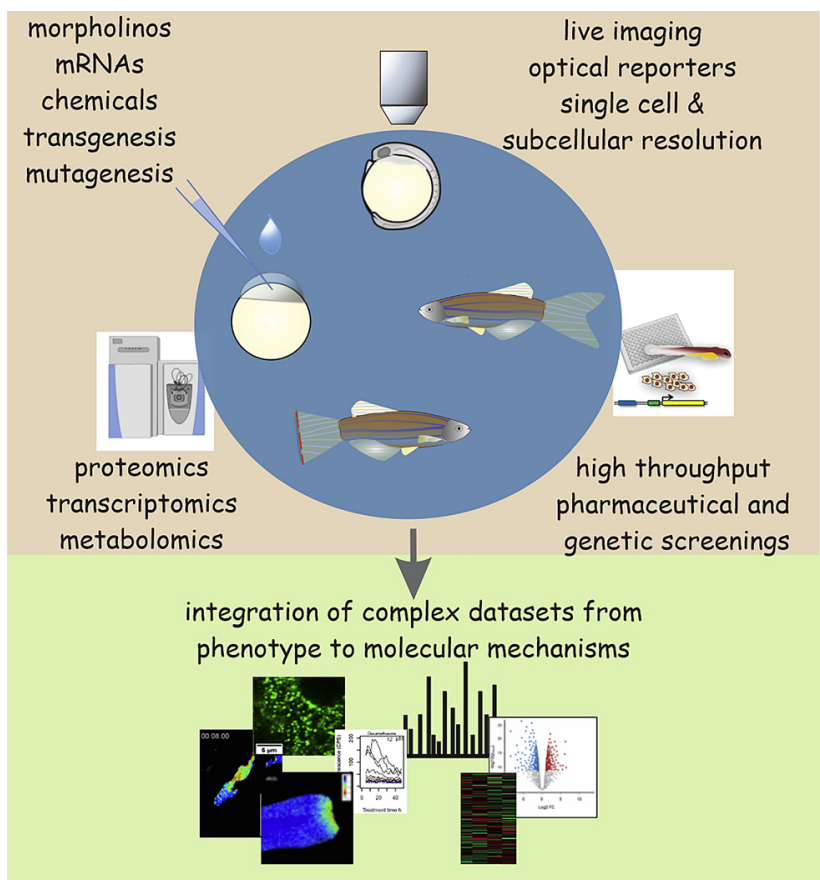

Figure 1: Zebrafish expressing genetic sensors serve as a tool guiding targeted manipulation and analysis of redox processes in development and regeneration.

nervous system. Retinal ganglion cells begin to form and their axons grow towards the optic tectum, where they will form functional connections by $72 \mathrm{hpf}$ (Kita et al. 2015). At $48 \mathrm{hpf}$, embryos begin to hatch from their eggshells, the chorions, and at $120 \mathrm{hpf}$ they start to hunt for food. At around 3-4 weeks, the primordial gonads start to differentiate into testis or ovary, and sexual maturity is reached at the age of 3 months (Orban et al. 2009).

Importantly, many of the genes regulating embryonic patterning and tissue differentiation are conserved between zebrafish and mammals (Schier and Talbot 2005; Solnica-Krezel and Sepich 2012; Yabe and Takada 2016; Zinski et al. 2018), including genes of the Hedgehog (Hh), Bone Morphogenetic Protein (BMP), Nodal, Fibroblast Growth Factor (FGF), Wnt, retinoic acid (RA) and NotchDelta pathways. Zebrafish studies have provided insight, for example, into functions of the TGF $\beta$-type Nodal signaling pathway in germ layer specification and left-right asymmetry (Zinski et al. 2018). In addition to conserved players and interactions, differently organized network features have been revealed as well, which give us glimpses of the functional and evolutionary plasticity of such regulatory networks (Pogoda and Hammerschmidt 2009; Yabe and Takada 2016). Notably, the possibility in zebrafish of observing the development of different embryonic stem cell populations in vivo and to follow the differentiation trajectories of their progeny already allows for insights that may inform the development of stem cell therapies for human patients (Perlin et al. 2017; Sutcu and Ricchetti 2018).

\section{The zebrafish as a model system for regeneration}

Resident stem cell populations also play a major role in the regeneration of many adult tissues after injury (Mokalled and Poss 2018; Marques et al. 2019). Due to its strong regenerative capacity upon tissue damage, contrasting with the limited capabilities of mammals, the zebrafish has become a model of choice to study regeneration in a variety of tissues, including kidney, liver, pancreas, brain, spinal cord, heart and fins (Marques et al. 2019). A better understanding of the molecular mechanisms allowing for tissue regeneration in the so-called "lower" vertebrates may give cues on how to improve or even launch regenerative processes in species with limited tissue regeneration capacities, such as ourselves (Iismaa et al. 2018; Marques et al. 2019).

The regeneration process easiest to study in zebrafish is probably fin regeneration, which is initiated for example by clipping of the distal part of the tail fin (Sehring and Weidinger 2020). In an initial wound response, leukocytes are recruited and the wound is closed by an epidermal cap. Then a so-called blastema is formed in the underlying tissue. This mass of dedifferentiated cells proliferates and its cells differentiate into the missing tissue types as regeneration proceeds. Similar processes of wound response and the formation of an underlying blastema-like tissue can also be observed upon regeneration of the larval fin fold (Kawakami et al. 2004; Mateus et al. 2012; Roehl 2018). Dedifferentiation and proliferation followed by redifferentiation equally occur during heart regeneration, as shown by lineage tracing studies that revealed preexisting cardiomyocytes as the source of the new tissue (Jopling et al. 2010; Kikuchi et al. 2010). Also transdifferentiation processes are possible: for example, pancreatic $\beta$-cells can be regenerated from $\alpha$-cells (Lu et al. 2016). Following a different strategy, regeneration of injured brain tissue, for example upon a stab wound to the telencephalon, requires the activation of neural stem cells, which are radial glia cells of the ventricular zone (Schmidt et al. 2013; Zambusi and Ninkovic 2020).

A few common insights emerge from these studies. All regeneration requires proliferation of precursors and differentiation into the cell types of the destroyed tissue, with differences between tissues mainly in the origin of the 
precursors (stem cells or dedifferentiation) and the differentiation trajectories (re- or transdifferentiation). These processes frequently reemploy signaling molecules and networks active during embryonic development (Cardozo et al. 2017; Sehring and Weidinger 2020; Yang and Kang 2019), either in the same organ (e.g. transcription factors involved in anterior-posterior patterning of limb buds (Nachtrab et al. 2013)) or in another context (e.g. simplet/ Fam35B, a regulator of Wnt signaling, newly expressed during larval and adult fin regeneration (Kizil et al. 2009, 2014)). Interestingly, enhancer elements driving injury induced expression of leptin $b$ in zebrafish can still be activated in mice, suggesting a conserved upstream regulatory network that in mammals has been uncoupled from regeneration-inducing processes, but could potentially be employed to stimulate regeneration (Kang et al. 2016; Yang and Kang 2019).

Two other common themes in regeneration are particularly pertinent to the topic of this review. First, the nervous system plays a crucial role in several regeneration processes, because denervation or inhibition of neural activity can impair regeneration (Mahmoud et al. 2015; Simoes et al. 2014). Second, the immune system and the inflammatory response mounted by it have been shown to play important roles in brain, spinal cord, heart and fin regeneration (Bosak et al. 2018; Martins et al. 2019; Marques et al. 2019; Petrie et al. 2014). Among the mechanisms implicated in these functions is the production and sensing of reactive oxygen species, as we will discuss in further detail below.

\section{Reactive oxygen species and their role in cellular signaling processes}

Reactive oxygen species (ROS) comprise several small molecules containing oxygen which easily engage in redox reactions, such as the hydroxyl radical $(\mathrm{OH} \cdot)$, the superoxide anion $\left(\mathrm{O}_{2}{ }^{-}\right)$or hydrogen peroxide $\left(\mathrm{H}_{2} \mathrm{O}_{2}\right)$. ROS are produced, for example, in the mitochondria (Wong et al. 2017) or by membrane bound NADPH-dependent oxidases (Nox1-5 and Duox1-2) that generate superoxide anions on the non-cytoplasmic side of the membrane (Panday et al. 2015). Superoxide dismutase enzymes convert superoxide anions to $\mathrm{O}_{2}$ and $\mathrm{H}_{2} \mathrm{O}_{2}$, while catalase degrades $\mathrm{H}_{2} \mathrm{O}_{2}$ to water and $\mathrm{O}_{2}$ (Glorieux and Calderon 2017; Winterbourn 2020). High levels of ROS causing DNA damage and oxidation of proteins and lipids classically have been implicated in metabolic diseases and ageing. This somewhat simplistic view of "oxidative stress" has recently been modified, arguing for "antagonistic pleiotropy" of ROS functions partially based on clinical observations that global antioxidant treatments were not successful in prevention or amelioration of several diseases or even had detrimental effects (Bjelakovic et al. 2007; Ristow et al. 2009; Sies and Jones 2020). Furthermore, recent redox proteomics studies of ageing rather found a remodeling of redox signaling networks than a global increase of thiol oxidation (Menger et al. 2015; Xiao et al. 2020). Consistently, ROS molecules are now known to play important roles in cellular signaling under physiological conditions (Finkel 2011; Schieber and Chandel 2014; Sies et al. 2017; Sies and Jones 2020).

A whole network of proteins serve as ROS scavengers and regulators of the oxidation state of proteins in the cell via the thiol residues of specific cysteines (Cys). Peroxiredoxins (Prxs) can reduce peroxides including $\mathrm{H}_{2} \mathrm{O}_{2}$, and they themselves are reduced by interaction with thioredoxins (Trxs) and glutaredoxins (Grxs), which also target other proteins (Hanschmann et al. 2013). Glutaredoxins take their reduction equivalents from glutathione, a peptide composed of cysteine, glycine, and glutamate, the latter bound via its $\gamma$-carboxylgroup. Its reduced form (GSH) is abundant in the cell and forms a redox couple with its disulfide form GSSG. Glutathione peroxidase family members use GSH to reduce $\mathrm{H}_{2} \mathrm{O}_{2}$ or organic hydroperoxides (Margis et al. 2008). Glutathione reductases reduce GSSG, while thioredoxin reductases reduce oxidized forms of thioredoxins (Hanschmann et al. 2013). Both reductase classes derive reduction equivalents from NADPH, generated for example in the pentose phosphate cycle. NADPH thus can serve both to produce (via Nox enzymes) and to scavenge $\mathrm{H}_{2} \mathrm{O}_{2}$.

By regulating the oxidation state of key residues in cellular signaling proteins, the components of this system directly influence signaling pathways (Finkel 2011; Holmstrom and Finkel 2014; Sies et al. 2017). For example, the Wnt signaling pathway component Dishevelled is bound by the thioredoxin-like nucleoredoxin under reduced conditions, thereby inhibiting Wnt signaling (Funato et al. 2006). Similarly, the nuclear localization of the transcription factor Nrf2, a component of the oxidative stress response, is regulated by the oxidation state of Keap1. Oxidized Keap1 cannot target Nrf2 for ubiquitination and subsequent degradation, so that it accumulates and localizes to the nucleus (Zhang and Hannink 2003). Signaling pathways can also use $\mathrm{H}_{2} \mathrm{O}_{2}$ as a second messenger (Holmstrom and Finkel 2014), and recent findings suggest that peroxiredoxins may play a widespread role in relaying this $\mathrm{H}_{2} \mathrm{O}_{2}$ signal to target proteins (Stocker et al. 2018a; Stocker et al. 2018b). 


\section{Genetically encoded sensors for imaging of $\mathrm{H}_{2} \mathrm{O}_{2}$ levels in vivo}

To fully understand the roles that $\mathrm{H}_{2} \mathrm{O}_{2}$, other ROS species and redox state play in cellular signaling and other physiological processes, information on their spatiotemporal dynamics in vivo is needed. By now, there exists a plethora of small compounds for imaging of various redox species (for an overview, see Hernandez-Garcia et al. 2010; Winterbourn 2014; Zielonka and Kalyanaraman 2018). While their application appears straightforward, there are a number of caveats that have to be considered especially when applying them in vivo. Thus, the penetration capacity of such sensors into tissues or embryos may be limited, they may be subject to sequestration into particular cell compartments or alter cellular functions. Some sensors are restricted by slow reaction kinetics or by auto-oxidation processes creating a high background level. Finally, specificity is often low, such that these molecules can sometimes be used only as indicators for a general presence of ROS, but not for a certain species.

Compared with these drawbacks, genetically encoded sensors can be better targeted to certain tissues, cells or subcellular compartments (Schwarzlander et al. 2016). Their usually well-developed reversibility and reaction kinetics allow for rapid dynamic measurements (which can, however, be a drawback if one is aiming to measure cumulative levels of ROS production in a tissue and cannot continuously monitor the specimen). When combined with specific redox-related proteins, they can achieve high specificity for a particular ROS species. We here discuss the two families of genetically encoded sensors that have so far been used most frequently in zebrafish studies (Table 1).

\section{HyPer sensors}

One broadly used type of genetically encoded sensor for redox state alterations is based on circularly permutated fluorescent proteins (cpFPs) (Kostyuk et al. 2019). In cpFPs, the original protein ends are fused and new termini generated at another place in the sequence while maintaining the overall structure. When now fused to sensor proteins, the more flexible structure of the cpFPs allows the transmission of structural alterations in the sensor moieties to the fluorophore, thereby affecting its spectral properties. The HyPer-type sensors widely used in redox imaging studies consist of a circularly permutated Yellow Fluorescent Protein (cpYFP) that is fused to the regulatory domain of the redox-sensitive bacterial transcription factor OxyR.
Table 1: Overview of genetically encoded thiol redox-sensor variants used in zebrafish studies.

\begin{tabular}{|c|c|c|c|}
\hline Sensor & Target & Comments & Zebrafish examples \\
\hline HyPer & $\mathrm{H}_{2} \mathrm{O}_{2}$ & Sensitive to $\mathrm{pH}$ & $\begin{array}{l}\text { Gauron et al. (2016), } \\
\text { Han et al. (2014), } \\
\text { Meda et al. (2016), } \\
\text { Niethammer et al. } \\
\text { (2009), Pase et al. } \\
\text { (2012) }\end{array}$ \\
\hline HyPer3 & $\mathrm{H}_{2} \mathrm{O}_{2}$ & $\begin{array}{l}\text { Sensitive to } \mathrm{pH} \text {, } \\
\text { higher amplitude } \\
\text { than HyPer }\end{array}$ & Bilan et al. (2013) \\
\hline HyPer7 & $\mathrm{H}_{2} \mathrm{O}_{2}$ & $\begin{array}{l}\mathrm{pH} \text {-insensitive, } \\
\text { higher sensitivity } \\
\text { than other HyPers }\end{array}$ & Pak et al. (2020) \\
\hline SypHer & $\mathrm{pH}$ & $\begin{array}{l}\text { Control for HyPer } \\
\text { sensors, redox- } \\
\text { insensitive }\end{array}$ & $\begin{array}{l}\text { Ermakova et al. } \\
\text { (2018) [SypHer3s] }\end{array}$ \\
\hline roGFP2 & $\mathrm{H}_{2} \mathrm{O}_{2}$ & $\begin{array}{l}\text { Reduced by endoge- } \\
\text { nous Grx }\end{array}$ & $\begin{array}{l}\text { O’Donnell et al. } \\
\text { (2013) }\end{array}$ \\
\hline roGFP2-Orp1 & $\mathrm{H}_{2} \mathrm{O}_{2}$ & $\begin{array}{l}\text { Less sensitive than } \\
\text { TSA } 2 \Delta C_{R} \text { - based } \\
\text { sensors }\end{array}$ & $\begin{array}{l}\text { Panieri et al. (2017), } \\
\text { Panieri and Santoro } \\
\text { (2017), Weaver et al. } \\
\text { (2018) }\end{array}$ \\
\hline Grx1-roGFP2 & $\begin{array}{l}\text { GSH/ } \\
\text { GSSG }\end{array}$ & & $\begin{array}{l}\text { Brautigam et al. } \\
\text { (2016), Panieri et al. } \\
\text { (2017), Panieri and } \\
\text { Santoro (2017), Seiler } \\
\text { et al. (2012) }\end{array}$ \\
\hline
\end{tabular}

Oxidation of key Cys residues in OxyR in the presence of $\mathrm{H}_{2} \mathrm{O}_{2}$ leads to conformational changes that alter the excitation properties of the cpYFP, allowing for a ratiometric measurement of OxyR oxidation state. Improved variants of the original HyPer sensor have been created, such as HyPer-3 (Bilan et al. 2013), which shows a higher dynamic range.

Owing to their less rigid structure, cpFPs are more susceptible to environmental changes than their nonpermutated counterparts, and this may manifest itself for example in a pH-dependence of the signal (Figure 2). Therefore, a mutated HyPer sensor variant has been developed (SypHer (Poburko et al. 2011) and subsequent variants (Ermakova et al. 2018; Matlashov et al. 2015)), which carries a mutation of the key Cys199 of the OxyR moiety that renders it insensitive to $\mathrm{H}_{2} \mathrm{O}_{2}$ induced oxidation and reveals the $\mathrm{pH}$-dependent component of the signal, with higher $\mathrm{pH}$ leading to higher ratio values. It thereby also doubles as a pH sensor in its own right. Very recently, yet another generation of HyPer based on the Neisseria meningitidis OxyR and a mutated cpYFP version with a GFP chromophore sequence has been generated that is more 


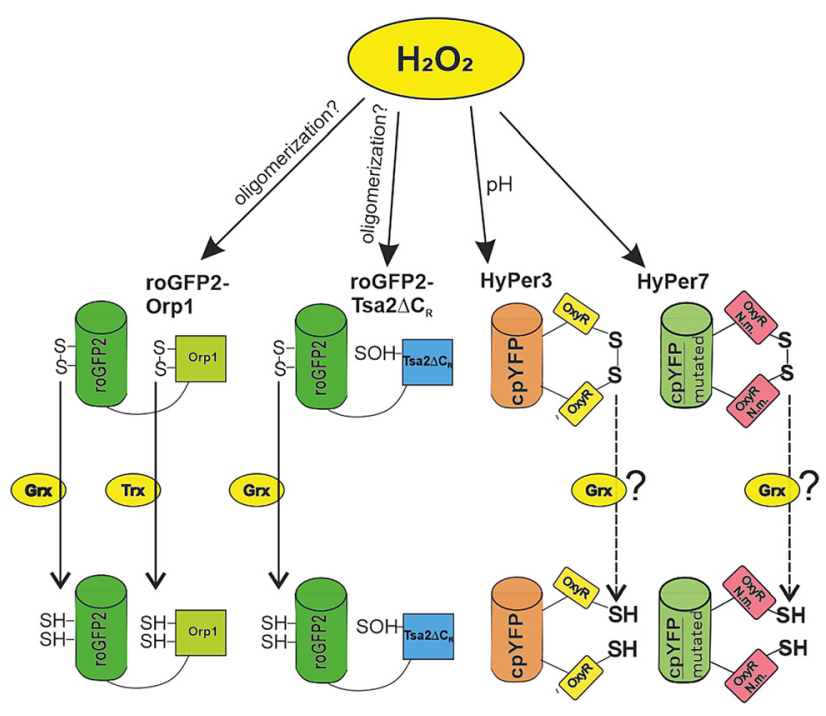

Figure 2: Protein redox sensors report altered redox state of their reactive cysteines, which depends on their reactivity with specific oxidants and the activity of endogenous thiol reactive redox systems, such thioredoxins (Trx) and glutaredoxins (Grx). Moreover, sensor properties can be sensitive to other parameters such as $\mathrm{pH}$ or sensor oligomerization. Thereby, sensor function may be influenced by particular cellular environments. N.m., Neisseria meningitides.

sensitive to $\mathrm{H}_{2} \mathrm{O}_{2}$ and lacks the $\mathrm{pH}$ sensitivity of the original sensors (HyPer7 (Pak et al. 2020)). This sensor represents a promising tool for $\mathrm{H}_{2} \mathrm{O}_{2}$ monitoring that would avoid the need for parallel acquisition of $\mathrm{pH}$-dependent changes by the SypHer sensors.

\section{roGFP-based sensors}

Another type of genetically encoded redox sensors uses a different functional principle. These sensors are based on the redox-sensitive fluorescent proteins roGFP1 and roGFP2, which alter their fluorescent properties dependent on the oxidation or reduction of key Cys residues and thereby enable ratiometric measurement of their oxidation status (Schwarzlander et al. 2016). The roGFPs alone equilibrate with the glutathione redox couple GSH/GSSG, catalyzed by endogenous Grxs. To circumvent this dependence on endogenous proteins, the roGFP moiety can be fused to a redox-sensitive sensor protein moiety which transfers its oxidation state to the Cys residues of roGFP, thereby providing information on the specific redox systems modifying the sensor part. Thus, by directly linking the mammalian Grx1 to roGFP2, the Grx1-roGFP2 sensor measures glutathione redox potential independently of the presence or activity of endogenous Grxs (Gutscher et al.
2008). $\mathrm{H}_{2} \mathrm{O}_{2}$ was targeted by the fusion of the yeast atypical 2-Cys peroxiredoxin Orp1 to roGFP2 (Delaunay et al. 2002; Gutscher et al. 2009). Sensor redox state of this roGFP2-Orp1 sensor is additionally influenced by endogenous Grx (as for roGFP2 alone) and Trx systems, which allow for reversibility of its oxidation by $\mathrm{H}_{2} \mathrm{O}_{2}$ under physiological conditions (Figure 2). The yeast peroxiredoxin Tsa2 was employed to generate a more sensitive $\mathrm{H}_{2} \mathrm{O}_{2}$ sensor version (Morgan et al. 2016). In the Tsa $2 \Delta C_{R}$ mutant used for the sensor, a resolving Cys has been mutated that renders it insensitive to thioredoxin based reduction, thereby increasing its sensitivity to $\mathrm{H}_{2} \mathrm{O}_{2}$ (Figure 2).

Compared to cpFP-based sensors, roGFP-type sensors have chromophores which are solvent inaccessible and therefore intrinsically more resistant to environmental conditions such as $\mathrm{pH}$. Consequently, the ratiometric properties of roGFP based sensors are stable within physiological pH ranges (Schwarzlander et al. 2008). However, the interaction with endogenous redox systems may alter sensor properties in different cell types or compartments, depending on the particular GSH/GSSG levels and Grx/Trx system activities present locally, and this feature should be considered when sensor results are interpreted. As the same redox systems also interact with HyPer probes, this caveat applies to them as well (Schwarzlander et al. 2016) (Figure 2). Another unknown for peroxiredoxin-based sensors is whether conditions in different organisms, tissues or cell compartments affect their oligomerization state, which influences oxidation sensitivity, and how this could impact sensor function (Pastor-Flores et al. 2020).

\section{$\mathrm{H}_{2} \mathrm{O}_{2}$ dynamics and zebrafish development}

Redox alterations have long been linked to development. Classical studies by Child used redox sensitive dyes to visualize what he referred to as metabolic gradients in embryos, including the zebrafish (Blackstone 2006; Child 1945). More recently, mitochondria-associated redox activities have been implicated in axis specification in early sea urchin embryos (Coffman and Denegre 2007; Coffman et al. 2009). Interestingly, these processes were linked to Nodal signaling, which plays a role in axis specification and germ layer patterning in vertebrates as well (Zinski et al. 2018). Numerous studies describe the impact of ROS on stem cell behavior, where higher ROS levels are generally associated with differentiation processes, but may also regulate quiescence-proliferation transitions (Bigarella et al. 2014; Prozorovski et al. 2015). Among the 
differentiation processes regulated by redox signaling are also axonal growth and neural cell migration (OlguinAlbuerne and Moran 2018; Wilson et al. 2018). Comparatively few studies have examined these aspects of redox biology in vivo. In particular, data are needed regarding spatiotemporal dynamics of ROS levels or of local redox potential changes, in order to identify potential ROS sources and to link them to downstream signaling networks. In the past few years, the first studies applying the genetic sensors introduced above to the zebrafish model system have begun to explore such questions.

Gauron et al. (2016) used HyPer driven by a ubiquitous promoter to examine $\mathrm{H}_{2} \mathrm{O}_{2}$ levels during embryonic development up to $72 \mathrm{hpf}$. High levels of sensor signal were recorded particularly during somitogenesis and organogenesis stages, which was attributed to decreased $\mathrm{H}_{2} \mathrm{O}_{2}$ degradation based on activity measurements of catalase from embryonic extracts. Higher signal levels were observed in the nervous system, and treatment with Nox inhibitors affected the size of the projection area of retinal ganglion cell axons in the tectum. The projection deficit could be rescued by treatment with an agonist of the Hedgehog pathway, implicating this signaling pathway as a downstream target of Nox-produced $\mathrm{H}_{2} \mathrm{O}_{2}$. Support for a role of Nox enzymes in the regulation of retinal projections also comes from a more recent genetic study by Weaver et al. (2018). Examining chimeric mutants of nox2/cybb, in which not all cells are homozygous for the mutation, the authors implicated this Nox in the proper development of the retinal projections to the optic tectum. However, using transient expression of the roGFP-orp1 sensor, they did not observe differences in $\mathrm{H}_{2} \mathrm{O}_{2}$ levels in homozygous mutants at $48 \mathrm{hpf}$ nor in cultured retinal ganglion cells derived from them, which they interpret as reflecting compensatory regulation by other Nox isoforms. This would fit to the observation that, in contrast to the chimeric mutants, tectal innervation was not decreased in homozygous mutants (although axons were mistargeted within and outside the tectum). Thus, while both studies support a role of Nox enzymes in development of the visual system connections in the brain, it remains unclear how precisely the production and distribution of $\mathrm{H}_{2} \mathrm{O}_{2}$ regulates the downstream processes. As HyPer sensors are sensitive to $\mathrm{pH}$ as well, it will be important to examine if SypHer sensors show overlapping patterns of ratio changes (see for example data obtained with SypHer3s in Ermakova et al. (2018). roGFP2-orp1 is not affected by $\mathrm{pH}$, but may not have been sensitive enough to pick up the differences between wildtypes and nox2/cybb mutants. Applying the next generation of sensors, HyPer7 (Pak et al. 2020) and roGFP2-
Tsa2 $\Delta C_{R}$ (Morgan et al. 2016), should help to resolve these issues.

HyPer imaging was also employed to examine retinal progenitor cell differentiation (Albadri et al. 2019). HyPer oxidation signals in the retina were uniformly high at $24 \mathrm{hpf}$ and declined in the central part of the retina by $32 \mathrm{hpf}$, concomitant with the differentiation of the tissue. These patterns are proposed to be shaped by differential expression of superoxide dismutase (sod2) and catalase in the tissue. $\mathrm{H}_{2} \mathrm{O}_{2}$ may act via lipid peroxidation, notably the production of 9-hydroxystearic acid (9-HSA). Consistently, the small molecule sensor for lipid peroxidation, BODIPY-C11, showed increased oxidation at the site of stem and early progenitor cells, where also increased levels of 4-hydroxynonenal, an end product of lipid peroxidation, were observed. 9-HSA treatment maintained retinal progenitor cells in a proliferative state and prevented differentiation, which appears consistent with the proposed spatiotemporal pattern of $\mathrm{H}_{2} \mathrm{O}_{2}$ production. By inhibiting histone deacetylase 1 function, 9-HSA seems to activate Wnt and Notch pathways that stimulate proliferation and prevent differentiation, respectively. Interestingly, in the hindbrain, 9-HSA treatment rather reduced the number of proliferating cells, indicating that its effects on quiescence/ proliferation/differentiation transitions of stem and progenitor cells may be tissue-specific. As with the studies on the development of retinotectal projections, a precise understanding of the spatiotemporal distribution of $\mathrm{H}_{2} \mathrm{O}_{2}$ induced redox signaling awaits the application of $\mathrm{pH}$ insensitive sensors to this system, especially because dividing progenitor cells in the embryonic Xenopus retina show aerobic glycolysis, a metabolic feature that - like proliferation in general - has been associated with a more alkaline cytoplasmic pH (Agathocleous et al. 2012; Flinck et al. 2018).

roGFP2-based sensors have also been used in embryos and larvae for questions more related to disease modeling and drug screening than embryonic development per se. Thus, Grx1-roGFP2 sensors have been applied to cancer related questions, namely to examine crosstalk between redox state and the MTH1 enzyme, which detoxifies oxidized nucleotides and has been implicated in the tumor response to oxidative stress (Brautigam et al. 2016), and to study a zebrafish model of tissue invasion, the meltdown mutant (Seiler et al. 2012). This model showed interactions between redox signaling in intestinal epithelial cells and smooth muscle cell tension that promote invasion by the epithelial cells, a mechanism potentially relevant in metastasis. Furthermore, to generate new experimental models for examining redox changes in cardiovascular 
tissues, Panieri et al. (Panieri and Santoro 2017; Panieri et al. 2017) used Grx1-roGFP2 or roGFP2-Orp1 targeted to the cytoplasm, mitochondria or the nucleus in endothelial cells or cardiomyocytes of zebrafish embryos. As a proofof-principle for drug screening approaches, the lines could indicate compartment- and tissue-specific effects on the sensor state when treated with compounds targeting glutathione synthesis or the pentose phosphate pathway. However, this required concomitant treatment with $\mathrm{H}_{2} \mathrm{O}_{2}$ or the redox cycling agent menadione, as no alterations were observed in the absence of these treatments (except for differences in basal oxidation state of both sensor types between the compartments, with sensors most reduced in the nucleus and most oxidized in the mitochondria). Detection of endogenous changes in response to compound treatment may require the application of the more sensitive sensors mentioned above.

\section{$\mathrm{H}_{2} \mathrm{O}_{2}$ changes during regeneration in zebrafish}

The first imaging study using a genetically encoded redox sensor which addressed processes related to regeneration in the zebrafish examined the wound response to a cut in the tail fin of embryos (Niethammer et al. 2009). After an initial immediate tissue contraction, within about $15 \mathrm{~min}$ after the cut leukocytes were recruited to the wound site. Immediately upon amputation, a gradient of HyPer ratio values was visible in the surrounding tissue, with most oxidized values at the site of the cut. The signal started to become apparent at about $3 \mathrm{~min}$ post wounding at the wound margin and reached a peak at about $20 \mathrm{~min}$, upon which it slowly declined. Pharmacological Nox inhibition and morpholino oligonucleotide mediated knock-down of Duox reduced the sensor signal and prevented leukocyte recruitment. A follow-up study combining HyPer imaging with modelling approaches examined how far $\mathrm{H}_{2} \mathrm{O}_{2}$ may penetrate from the wound margin into the surrounding tissue before it becomes inactivated by antioxidant activities (Jelcic et al. 2017). Peak (extracellular) levels at the wound margin were estimated to not exceed $5 \mu \mathrm{M}$. With modelling indicating that antioxidant reactions should become exhausted above $2 \mu \mathrm{M}$, it was estimated that such high concentrations occur up to $30 \mu \mathrm{m}$ away from the wound margin.

These findings were incorporated into a model of signaling by tissue wounds describing a sequence of events which starts with the immediate release of Damage Associated Molecular Pattern (DAMP) molecules such as ATP that may both serve as chemoattractants and trigger downstream signaling events related to inflammation. These processes include $\mathrm{Ca}^{2+}$ mediated signaling that stimulates production of ROS and polyunsaturated fatty acids (PUFAs), which then potentially serve as relay attractants that are more stable than the rapidly dissipated DAMPs (Niethammer 2016). Thus, $\mathrm{H}_{2} \mathrm{O}_{2}$ has been proposed to activate the Src family kinase Lyn and thereby recruit neutrophils (Yoo et al. 2011). However, the relatively limited penetration of sufficient high levels of $\mathrm{H}_{2} \mathrm{O}_{2}$ into the tissue suggested by Jelcic et al. (2017) calls for additional studies examining the importance of such a mechanism compared to other candidates for attractants acting downstream or in parallel of $\mathrm{H}_{2} \mathrm{O}_{2}$. Indicating potential common regulatory mechanisms, a link between early ROS production at the wound site and Src kinase signaling has also been proposed in organizing cell polarity for wound closure in early zebrafish embryos (Hunter et al. 2018) and for the regenerative response of epithelial cells in larval tail fin regeneration (via the Src kinase fynb (Yoo et al. 2012)). Additionally, ROS regulate vimentin expression via NfkB signaling, which is necessary for collagen-based projections at the wound edge that guide regenerative growth (LeBert et al. 2018).

The attraction of leukocytes to the wound is important for the subsequent regeneration processes. It has been proposed that the leukocytes may exert negative feedback on early wound signals, by lowering $\mathrm{H}_{2} \mathrm{O}_{2}$ levels via myeloperoxidase in neutrophils (as imaged using a transgenic line driving HyPer in this cell type (Pase et al. 2012)) and by an inhibitory effect of macrophages on expression of the cytokine IL1 $\beta$ in the wound epithelium (Hasegawa et al. 2017). The precise timing of these activities and their interplay with ROS triggered processes in the wound tissue itself may create an environment that allows regeneration to proceed (Roehl 2018).

The importance of ROS production for regeneration was equally suggested by studies in other regeneration models involving different tissues and species. Thus, HyPer imaging in Xenopus tadpole tails revealed similar gradients of sensor excitation ratio upon wounding as those observed in zebrafish (Love et al. 2013). Here, $\mathrm{H}_{2} \mathrm{O}_{2}$ production was sustained over the next few days while the tail regenerates. Tail fin regeneration was impaired upon lowering of $\mathrm{H}_{2} \mathrm{O}_{2}$ levels via pharmacological treatments with Nox inhibitors and ROS scavengers for three days post-amputation, as well as upon morpholino-mediated interference with expression of $c y b a$, a subunit of Nox complexes (Love et al. 2013). Downstream effects of this $\mathrm{H}_{2} \mathrm{O}_{2}$ production included the stimulation of proliferation via a Wnt/FGF20 signaling network. Interestingly, $\mathrm{H}_{2} \mathrm{O}_{2}$ production is also paralleled by increased $\mathrm{O}_{2}$ 
consumption in the regenerating tail, leading to stabilization of the hypoxia signaling factor HIFla by local hypoxia that influences regeneration in a parallel pathway (Ferreira et al. 2018).

Prolonged ROS production during regeneration was equally observed in adult tail fin regeneration in zebrafish employing small molecule sensor (DCF) imaging (Gauron et al. 2013). In this model, based on pharmacological Nox inhibition, ROS production was reported to be involved in apoptosis and JNK kinase regulation that are both required for compensatory cell proliferation. Also in the regenerative response of adult epithelial cells to superficial exfoliation lesions, ROS (as measured by the cell permeable fluorescent probe CellROX Green and likely derived from Noxs) were elevated for at least $24 \mathrm{~h}$ and required for the regeneration response, partially by regulating cell hypertrophy (Chen et al. 2016). Similarly, CellROX Orange indicated higher ROS levels in a model of chemical liver injury from $24 \mathrm{~h}$ after start of the treatment until at least $48 \mathrm{~h}$, concomitant with leukocyte recruitment (Stoddard et al. 2019). Furthermore, HyPer imaging in the adult zebrafish heart showed sustained increased sensor oxidation levels at 3, 7 and 14 days post injury (but not $1 \mathrm{~h}$ after the injury) in the epicardium and adjacent myocardium at the resection site (Han et al. 2014). These observations indicate that ROS may play distinct roles in various phases of different regeneration processes.

Identifying direct targets modified by $\mathrm{H}_{2} \mathrm{O}_{2}$ or other ROS at early and later stages during the wound response and regeneration should enable a better understanding of the signaling networks connecting the two processes. In zebrafish heart regeneration, $\mathrm{H}_{2} \mathrm{O}_{2}$ production by Duox was suggested to regulate MAPK signaling via a derepression mechanism involving the phosphatase Dusp6 primarily in the epicardium (Han et al. 2014). Interestingly, a redox proteomics study of adult fin regeneration identified another phosphatase, the protein tyrosine phosphatase Shp2, which is oxidized and thereby probably inactivated during regeneration (Wu et al. 2017). Surprisingly, it is also required for regeneration of the larval tail fin, as mutant embryos lacking Shp2 function do not regenerate. These findings highlight the complexity of the redox sensitive signaling networks regulating regeneration processes.

$\mathrm{H}_{2} \mathrm{O}_{2}$ was also implicated in axon regeneration into the larval fin (Rieger and Sagasti 2011). Axon activity (i.e., growth and retraction) of severed axons was transiently increased post tail fin amputation, but no further than $50 \mu \mathrm{m}$ from the injury, indicating a short range of a wound derived growth promoting signal. Additional experiments (including small molecule sensor imaging with
PFBS-F) showed that Duox-mediated $\mathrm{H}_{2} \mathrm{O}_{2}$ production in wound keratinocytes was required for axon regeneration, with $\mathrm{H}_{2} \mathrm{O}_{2}$ effects on macrophage recruitment to the wound and axon growth being independent of each other. Interestingly, the degeneration of the injured axon (Wallerian degeneration) shortly after the cut may require ROS production as well, namely in the mitochondria of the neurons, as assessed in zebrafish embryos transiently expressing roGFP2 targeted to this compartment (O'Donnell et al. 2013). Mitochondria in the severed distal axon part showed an increase in roGFP2 oxidation prior to the synchronous fragmentation of the disconnected axon part. Overexpression of the mitochondrial biogenesis regulator PGC- $1 \alpha$ correlated with reduced oxidation of roGFP2 upon axotomy and stabilized the severed axon part. Thus, distinct subcellular and cellular ROS sources appear to be involved in the wound and regeneration response of axons in zebrafish larvae.

Re-innervation not only is a regenerative response to amputation influenced by $\mathrm{H}_{2} \mathrm{O}_{2}$, nerves also are required for limb regeneration (Meda et al. 2018). In zebrafish adult fin regeneration, this seems to involve an increase of $\mathrm{H}_{2} \mathrm{O}_{2}$ production (measured with the small molecule sensor DCF and HyPer) in the fin tissue, apparently triggered via Hedgehog signaling from Schwann cells (Meda et al. 2016). The re-innervating axons then would suppress $\mathrm{H}_{2} \mathrm{O}_{2}$ levels in the fin again. Potentially indicating a common signaling mechanism upstream of $\mathrm{H}_{2} \mathrm{O}_{2}$ production, a link between Hedgehog signaling and $\mathrm{H}_{2} \mathrm{O}_{2}$ was recently also described for regeneration upon larval tail excision. In this model distinct from larval fin fold regeneration, the amputation is performed closer to the trunk, including not only the fin fold tissue but also touching the notochord and surrounding tissues (Romero et al. 2018). Here, $\mathrm{H}_{2} \mathrm{O}_{2}$ production (measured with the small molecule sensor PFBS-F and blocked with the Nox inhibitor DPI) in cells at the edge of the stump appears to regulate a pathway in which cells derived from the notochord sheath form a bead-like cluster at the cut site. This "notochord bead" releases Hedgehog signals which stimulate regeneration upstream of Wnt, FGF and RA signaling. On the other hand, in embryonic development Hedgehog signaling has been proposed to act downstream of Nox-derived $\mathrm{H}_{2} \mathrm{O}_{2}$ in the formation of retinotectal projections (Gauron et al. 2016). It will certainly be interesting to further examine these links by charting precise tissue and cell-type dynamics using both reporters for signaling pathways (Moro et al. 2013) and the more specific and sensitive next generation of genetically encoded redox sensors. 


\section{Current limitations of the genetically encoded sensors}

As evident from the previous paragraphs, the application of genetically encoded redox sensors has allowed us to address questions on subcellular, cellular and tissue distribution of $\mathrm{H}_{2} \mathrm{O}_{2}$ production in various developmental and regeneration processes; prompting also mechanistic insights into downstream pathways. However, many of the methods used for functional interference with ROS signaling or other molecular mechanisms and for the visualization of ROS have limitations that should be taken into consideration when interpreting the data.

(1) Small molecule sensors are often used to detect alterations in ROS levels, involving the limitations of specificity, stability and distribution in vivo discussed above. Along a similar line, enzyme activity is regularly inhibited using small molecules, which equally may be limited in their specificity and target other enzymes of the same family or unrelated proteins (Sorce et al. 2017).

(2) Morpholino oligonucleotides have been widely used to interfere with gene expression, generating "morphant" embryos. Experiments involving morpholinos are currently being re-evaluated because of frequently observed off-target effects and p53 mediated toxicity (Blum et al. 2015; Schulte-Merker and Stainier 2014). A recent study indicated that such off-target effects include increased expression of interferon stimulated genes and of components of cellular stress pathways, which might interfere with immune cell function, important in the context of regeneration (Lai et al. 2019). Thus, it is necessary to employ appropriate controls when using morpholinos (Stainier et al. 2017). Ideally, morphant phenotypes should be confirmed by other techniques, notably by generating mutants carrying suitable loss-of-function alleles. This has become possible more easily by the adaptation of CRISPR-Cas9 based systems to the zebrafish (Liu et al. 2019). However, mutants have their drawbacks as well, since genetic compensation mechanisms may mask the function(s) of the targeted gene, and mutants even may appear as wild-type (Blum et al. 2015; El-Brolosy et al. 2019; Rossi et al. 2015). In such cases, it should be confirmed that the mutant allele is indeed a loss-offunction allele and that mutants are resistant to morpholino-induced phenotypes.

(3) As mentioned above, the genetically encoded $\mathrm{H}_{2} \mathrm{O}_{2}$ sensors have their own set of limitations that are intrinsic to their properties and involve interactions with the cellular environment. We will now discuss these issues in more detail for the tail wound assay.

The $\mathrm{pH}$ sensitivity of the HyPer sensor makes it necessary to employ controls that allow one to correct for this property. The original study employing HyPer to visualize the wound response tested for $\mathrm{pH}$ alterations using YFP alone and a small molecule sensor (Niethammer et al. 2009), but these are not ideal controls due to different sensitivities and the general limitations of small molecule sensors. One way of confirming that redox and not only $\mathrm{pH}$ changes occur is to look for downstream effects that can be attributed to increased ROS presence. For example, in the embryonic retina, the observed sensor patterns were compared with signals for lipid peroxidation (Albadri et al. 2019). However, one still needs a control that allows an evaluation of the precise spatiotemporal patterns observed with HyPer. Ideally, one should always show a corresponding SypHer probe side by side to compare patterns of ratio changes. The ratiometric nature of the sensors is an advantage, as the ratio should not be subject to expression level variations that may occur in different transgenic lines or upon transient expression.

In the Xenopus tadpole tail wounding assay, $\mathrm{pH}$ alterations can be measured with SypHer2 that seem to occur in two phases, first a rapid acidification near the wound and then a more prolonged alkalinization at later stages (Matlashov et al. 2015). These observations indicate that there is not only a change in redox state, but also changes in intracellular $\mathrm{pH}$ levels that occur upon wounding. Interestingly, earlier work in Xenopus has implicated a proton pump, the V-ATPase, as a player in tail regeneration (Adams et al. 2007). V-ATPase pumps protons out of the cell, which can increase intracellular $\mathrm{pH}$ (Hinton et al. 2009). Consistently, the pH increase seen in SypHer2 expressing Xenopus tails was blocked by V-ATPase antagonists (but not the initial decrease (Matlashov et al. 2015)). V-ATPase activity is linked to changes in transmembrane voltage that are also important for regeneration. Additionally, alteration of bioelectric properties in tailbud regeneration has been described as occurring downstream of Nox activity (Ferreira et al. 2016), and also Nox/Duox enzymes can alter proton distributions (Ezerina et al. 2014). Thus, both $\mathrm{pH}$ and bioelectric changes may contribute to create a regeneration-specific state in the tail. Among the processes proposed to be triggered by bioelectric changes are axonal growth, proliferation and differentiation (Ferreira et al. 2016; Ferreira et al. 2018), and also relocation of myeloid cells and an increase in their antibacterial activity was observed in response to the depolarization at the site of 
the tail cut in Xenopus (Pare et al. 2017). In the zebrafish, $\mathrm{V}$-ATPase has been implicated in regeneration of the adult fin, where it is required for blastema cell proliferation and expression of RA and FGF signaling pathway components (Monteiro et al. 2014). By contrast, larvae homozygous for a mutant allele of the $a t p 6 v 1 e 1 b$ gene encoding a V-ATPase subunit showed no difference in fin fold regeneration from wild-types, which might indicate genetic compensation mechanisms or functional redundancy of other proton pumps in this system. Thus, it will be interesting to further dissect the relative contributions and connections of ROS, $\mathrm{pH}$ and bioelectric changes during regeneration processes using optical sensors and microelectrode based systems (including for example the scanning ion selective electrode technique [SIET] to measure extracellular $\mathrm{pH}$ (Lin et al. 2006)), and to examine their links with other signaling pathways involved in wound response and regeneration.

An intriguing observation is the presence of sensor ratio gradients upon tail fin wounding seen with the new HyPer7 sensor (Pak et al. 2020), which is more sensitive than previous HyPer versions and lacks $\mathrm{pH}$ dependency of the signal. This indicates that indeed a gradient of $\mathrm{H}_{2} \mathrm{O}_{2}$ may be present, but that it involves $\mathrm{H}_{2} \mathrm{O}_{2}$ levels about 30 times lower than originally estimated. The extracellular concentration of $5 \mu \mathrm{M} \mathrm{H}_{2} \mathrm{O}_{2}$ near the wound margin estimated based on HyPer data (Jelcic et al. 2017) would then translate to $0.2 \mu \mathrm{M}$ or less based on HyPer7 data. Would this concentration be sufficient for the attraction of leukocytes to the wound? Klyubin et al. (Klyubin et al. 1996) observed neutrophil chemotaxis toward a source of (1-) $10 \mu \mathrm{M} \mathrm{H} \mathrm{H}_{2} \mathrm{O}_{2}$ placed at a distance of a few millimeters in vitro; thus, given the shorter distances in the zebrafish tail fin, $0.2 \mu \mathrm{M}$ at the cut might still be high enough. However, it would be of interest to recalculate the local $\mathrm{H}_{2} \mathrm{O}_{2}$ concentrations needed to overcome the antioxidant barriers mentioned above (Jelcic et al. 2017) based on data obtained with the new sensor generation. The gradient of lower concentrations indicated by HyPer7 lends further support to the idea that relay mechanisms are needed for leukocyte attraction to the source of $\mathrm{H}_{2} \mathrm{O}_{2}$. Also, because $\mathrm{H}_{2} \mathrm{O}_{2}$ as well has been reported to inhibit neutrophil migration (Wang et al. 2016), its production at the wound site might help to trap the migrating leukocytes where they are needed, and to avoid overshooting migration across the tissue border.

\section{Conclusions and perspectives}

Our overview indicates that genetically encoded redoxsensors have been used successfully to study processes of embryonic development and regeneration, and some applications have also targeted disease models. However, explaining the distinct spatiotemporal dynamics of signals generated by the different sensor types still requires further studies, ideally in the presence and absence of artificially generated in vivo gradients of $\mathrm{ROS}, \mathrm{pH}$ and bioelectricity. An important unknown is to what extent the different sensor types interact differently with antioxidant and redox relay systems present in different tissues and cellular compartments. For example, the redox switch of OxyR has been reported to be less efficiently reduced by cellular reductants such as Grxs than it is oxidized, allowing prolonged induction of transcription upon $\mathrm{H}_{2} \mathrm{O}_{2}$ sensing (Aslund et al. 1999; Choi et al. 2001; Cremers and Jakob 2013), while roGFP2-Tsa2 $\triangle C_{R}$ is insensitive to reduction by Trxs (Morgan et al. 2016). Thus, there is a need for sensors systems that are able to separately and specifically monitor these enzymatic activities.

Among the many zebrafish models of human diseases in which ROS alterations have been implicated in pathogenesis are also those of endocrine diseases like diabetes (Di Marco et al. 2015; Gut et al. 2017). It has been shown in zebrafish larvae that different $\mathrm{H}_{2} \mathrm{O}_{2}$ levels can stimulate either proliferation or neogenesis of pancreatic $\beta$-cells, and it will be interesting to link these data with measurements of endogenous $\mathrm{H}_{2} \mathrm{O}_{2}$ levels under different nutritional challenges to further explore roles of $\mathrm{H}_{2} \mathrm{O}_{2}$ signaling in the regulation of $\beta$-cell mass (Ahmed Alfar et al. 2017). Sensor imaging might also help to further dissect the recently observed discrepancies in redox-regulated gene expression between zebrafish models of primary and secondary adrenal insufficiencies, diseases of glucocorticoid deficiency (Weger et al. 2018). Given the strong links between the circadian clock and ROS regulation (Putker and O'Neill 2016) (also apparent in the adrenal gland itself (Kil et al. 2012; Rhee and Kil 2016)), it will be important to consider time-of-day dependent effects when working with such older larval models (Weger et al. 2013, 2016).

Besides spatiotemporal monitoring, also spatiotemporal manipulation of ROS production will be important for a profound understanding of redox signaling in development, disease and regeneration. Tissue specific catalase overexpression to scavenge $\mathrm{H}_{2} \mathrm{O}_{2}$ has been used to examine heart regeneration and the formation of $\beta$-cells (Ahmed Alfar et al. 2017; Han et al. 2014). In a complementary approach, the D-amino acid oxidase (DAAO) enzyme that can be expressed tissue-specifically and targeted to particular cellular compartments allows localized $\mathrm{H}_{2} \mathrm{O}_{2}$ production upon addition of a D-amino acid, thereby enabling also temporal control (Bogdanova et al. 2017; Pak et al. 2020). Further developments here may target the regulation of specific ROS species. 
An important task will be the identification of effector molecules that translate $\mathrm{H}_{2} \mathrm{O}_{2}$ alterations into a biological response. Redox proteomics is a powerful tool that can identify direct targets of ROS species (Leichert et al. 2008; Lennicke et al. 2016; Topf et al. 2018), and can be combined with transcriptomics, proteomics and metabolomics approaches that comprehensively map downstream effects. The genetically encoded sensors can provide detailed information on spatiotemporal aspects of $\mathrm{H}_{2} \mathrm{O}_{2}$ signaling that can guide the choice of time points or tissues to which such methods are applied. Spatiotemporal mapping of transcriptome changes with cellular resolution by single cell RNA-seq approaches has been successfully used in the context of both development and regeneration in the zebrafish (Cosacak et al. 2019; Farrell et al. 2018; Lush et al. 2019; Spanjaard et al. 2018; Wagner et al. 2018). Combining such data with highly resolved single cell imaging of whole embryos into a digital embryo will enable to model cell movements and differentiation processes in unprecedented detail (Keller et al. 2008; Sladitschek et al. 2020), and such models could also incorporate redox sensor derived data. Isolating cells with specific redox signaling states for further studies could be accomplished using fluorescence activated cell sorting (FACS) based on sensor oxidation state, analogous to previous studies in zebrafish embryos targeting cells labelled according to signaling pathway activity, tissue identity or cell cycle phase (Dickmeis et al. 2001; Dickmeis et al. 2004; Wragg et al. 2020). However, FACS may alter the redox state of cells (Llufrio et al. 2018), so results should be compared with data obtained by laser capture microdissection (Veldman et al. 2007; Zoidl et al. 2004) or other nano-sampling techniques (Dickmeis et al. 2019). Such single-cell based analyses should allow to produce a clearer picture of which $\mathrm{H}_{2} \mathrm{O}_{2}$ effects in which tissues and cells are important for which developmental and regenerative processes.

It is still incompletely understood how $\mathrm{H}_{2} \mathrm{O}_{2}$ signals propagate, both extracellularly and intracellularly. While the intracellular aspects could be targeted by sensor imaging approaches under targeted manipulation of intracellular $\mathrm{H}_{2} \mathrm{O}_{2}$ sources (Pak et al. 2020), more information is needed on the spreading of $\mathrm{H}_{2} \mathrm{O}_{2}$ in the extracellular space. This task will require the development of optical sensors with specific properties adapted to the extracellular environment, or the application of redox sensitive microelectrode methods (Bozem et al. 2018). Also potential roles of mechanisms alternative to diffusion should be clarified, including the recently suggested distribution of ROS producing enzymes by microvesicles (Hervera et al. 2019) or perhaps the cytoneme-based spreading that has been proposed for morphogen transport (Kornberg 2014).
The zebrafish, with its unique potential to combine whole organism with (sub-)cellular imaging and molecular genetic studies, is likely to continue to further our understanding of redox processes in development and regeneration. A prerequisite for this is a detailed mechanistic understanding of the tools applied for visualization of ROS in vivo, and the application of multiple strategies to crossvalidate findings and to examine their upstream regulation and downstream consequences.

Acknowledgments: We thank Philipp Gut and Andrea Schink for a critical reading of the manuscript. We are grateful to Miriam Otto for help with figure preparation. We apologize to those colleagues whose work could not be cited due to space constraints and refer the reader to the cited review articles for further information on the primary literature.

Author contribution: All the authors have accepted responsibility for the entire content of this submitted manuscript and approved submission.

Research funding: Research in the Dickmeis lab is funded by the Schwerpunktprogramm SPP1710 "Dynamics of Thiol-based Redox Switches in Cellular Physiology" (DI913/6-1) and the Graduiertenkolleg GRK2039 "Molecular Architectures for Fluorescent Imaging of Cells" of the Deutsche Forschungsgemeinschaft, by the "Effect-Net" research network in water research of the Ministerium für Wissenschaft, Forschung und Kunst Baden-Württemberg, and by the Helmholtz Programme BioInterfaces in Technology and Medicine (BIFTM).

Conflict of interest statement: The authors declare no conflicts of interest regarding this article.

\section{References}

Adams, D.S., Masi, A., and Levin, M. (2007). H+ pump-dependent changes in membrane voltage are an early mechanism necessary and sufficient to induce Xenopus tail regeneration. Development 134: 1323-35.

Agathocleous, M., Love, N.K., Randlett, O., Harris, J.J., Liu, J., Murray, A.J., and Harris, W.A. (2012). Metabolic differentiation in the embryonic retina. Nat. Cell Biol. 14: 859-64.

Ahmed Alfar, E., Kirova, D., Konantz, J., Birke, S., Mansfeld, J., and Ninov, N. (2017). Distinct levels of reactive oxygen species coordinate metabolic activity with $\beta$-cell mass plasticity. Sci. Rep. 7: 3994.

Albadri, S., Naso, F., Thauvin, M., Gauron, C., Parolin, C., Duroure, K., Vougny, J., Fiori, J., Boga, C., Vriz, S., et al. (2019). Redox signaling via lipid peroxidation regulates retinal progenitor cell differentiation. Dev. Cell 50: 73-89 e6.

Aslund, F., Zheng, M., Beckwith, J., and Storz, G. (1999). Regulation of the OxyR transcription factor by hydrogen peroxide and the 
cellular thiol-disulfide status. Proc. Natl. Acad. Sci. U.S.A. 96: 6161-5.

Bambino, K. and Chu, J. (2017). Zebrafish in toxicology and environmental health. Curr. Top. Dev. Biol. 124: 331-367.

Bigarella, C.L., Liang, R., and Ghaffari, S. (2014). Stem cells and the impact of ROS signaling. Development 141: 4206-18.

Bilan, D.S., Pase, L., Joosen, L., Gorokhovatsky, A.Y., Ermakova, Y.G., Gadella, T.W., Grabher, C., Schultz, C., Lukyanov, S., and Belousov, V.V. (2013). HyPer-3: a genetically encoded H(2)O(2) probe with improved performance for ratiometric and fluorescence lifetime imaging. ACS Chem. Biol. 8: 535-42.

Bjelakovic, G., Nikolova, D., Gluud, L.L., Simonetti, R.G., and Gluud, C. (2007). Mortality in randomized trials of antioxidant supplements for primary and secondary prevention: systematic review and meta-analysis. J. Am. Med. Assoc. 297: 842-57.

Blackstone, N.W. (2006). Charles Manning Child (1869-1954): the past, present, and future of metabolic signaling. J. Exp. Zool. B Mol. Dev. Evol. 306: 1-7.

Blum, M., De Robertis, E.M., Wallingford, J.B., and Niehrs, C. (2015). Morpholinos: antisense and sensibility. Devopmental Cell 35: 145-9.

Bogdanova, Y.A., Schultz, C., and Belousov, V.V. (2017). Local generation and imaging of hydrogen peroxide in living cells. Current Protocols in Chemical Biology 9: 117-127.

Bollmann, J.H. (2019). The zebrafish visual system: from circuits to behavior. Annual Review of Vision Science 5: 269-293.

Bosak, V., Murata, K., Bludau, O., and Brand, M. (2018). Role of the immune response in initiating central nervous system regeneration in vertebrates: learning from the fish. Int. J. Dev. Biol. 62: 403-417.

Bozem, M., Knapp, P., Mirceski, V., Slowik, E.J., Bogeski, I., Kappl, R., Heinemann, C., and Hoth, M. (2018). Electrochemical quantification of extracellular local $\mathrm{H}_{2} \mathrm{O}_{2}$ kinetics originating from single cells. Antioxidants Redox Signal. 29: 501-517.

Brautigam, L., Pudelko, L., Jemth, A.S., Gad, H., Narwal, M., Gustafsson, R., Karsten, S., Carreras Puigvert, J., Homan, E., Berndt, C., et al. (2016). Hypoxic signaling and the cellular redox tumor environment determine sensitivity to MTH1 inhibition. Cancer Reserach 76: 2366-75.

Cardozo, M.J., Mysiak, K.S., Becker, T., and Becker, C.G. (2017). Reduce, reuse, recycle - developmental signals in spinal cord regeneration. Dev. Biol. 432: 53-62.

Chen, C.H., Puliafito, A., Cox, B.D., Primo, L., Fang, Y., Di Talia, S., and Poss, K.D. (2016). Multicolor cell barcoding technology for longterm surveillance of epithelial regeneration in zebrafish. Dev. Cell 36: 668-80.

Child, C.M. (1945). A further study of oxidation-reduction pattern in teleost development. J. Exp. Zool.: 577-589, https://doi.org/10. 1002/jez.1401000317.

Choi, H., Kim, S., Mukhopadhyay, P., Cho, S., Woo, J., Storz, G., and Ryu, S.E. (2001). Structural basis of the redox switch in the OxyR transcription factor. Cell 105: 103-13.

Chow, R.W. and Vermot, J. (2017). The rise of photoresponsive protein technologies applications in vivo: a spotlight on zebrafish developmental and cell biology. F1000Research 6, https://dx. doi.org/10.12688\%2Ff1000research.10617.1.

Coffman, J.A., Coluccio, A., Planchart, A., and Robertson, A.J. (2009). Oral-aboral axis specification in the sea urchin embryo III. Role of mitochondrial redox signaling via H2O2. Dev. Biol. 330: 123-30.
Coffman, J.A. and Denegre, J.M. (2007). Mitochondria, redox signaling and axis specification in metazoan embryos. Dev. Biol. 308: 266-80.

Cosacak, M.I., Bhattarai, P., Reinhardt, S., Petzold, A., Dahl, A., Zhang, Y., and Kizil, C. (2019). Single-cell transcriptomics analyses of neural stem cell heterogeneity and contextual plasticity in a zebrafish brain model of amyloid toxicity. Cell Rep. 27: 1307-1318 e3.

Cremers, C.M. and Jakob, U. (2013). Oxidant sensing by reversible disulfide bond formation. J. Biol. Chem. 288: 26489-96.

Davis, E.E. and Katsanis, N. (2017). Zebrafish: a model system to study the architecture of human genetic disease. In: Conn, P. M. (Ed.), Animal models for the study of human disease, 2 nd ed.: Academic Press.

Delaunay, A., Pflieger, D., Barrault, M.B., Vinh, J., and Toledano, M.B. (2002). A thiol peroxidase is an $\mathrm{H}_{2} \mathrm{O}_{2}$ receptor and redoxtransducer in gene activation. Cell 111: 471-81.

Di Marco, E., Jha, J.C., Sharma, A., Wilkinson-Berka, J.L., Jandeleit-Dahm, K.A., and De Haan, J.B. (2015). Are reactive oxygen species still the basis for diabetic complications? Clin. Sci. (Lond.) 129: 199-216.

Dickmeis, T., Aanstad, P., Clark, M., Fischer, N., Herwig, R., Mourrain, P., Blader, P., Rosa, F., Lehrach, H., and Strahle, U. (2001). Identification of nodal signaling targets by array analysis of induced complex probes. Dev. Dynam. 222: 571-80.

Dickmeis, T., Feng, Y., Mione, M.C., Ninov, N., Santoro, M., Spaink, H.P., and Gut, P. (2019). Nano-sampling and reporter tools to study metabolic regulation in zebrafish. Frontiers in Cell and Developmental Biology 7, https://doi.org/10.3389/fcell. 2019.00015.

Dickmeis, T., Plessy, C., Rastegar, S., Aanstad, P., Herwig, R., Chalmel, F., Fischer, N., and Strahle, U. (2004). Expression profiling and comparative genomics identify a conserved regulatory region controlling midline expression in the zebrafish embryo. Genome Res. 14: 228-38.

El-Brolosy, M.A., Kontarakis, Z., Rossi, A., Kuenne, C., Gunther, S., Fukuda, N., Kikhi, K., Boezio, G.L.M., Takacs, C.M., Lai, S.L., et al. (2019). Genetic compensation triggered by mutant mRNA degradation. Nature 568: 193-197.

Ermakova, Y.G., Pak, V.V., Bogdanova, Y.A., Kotlobay, A.A., Yampolsky, I.V., Shokhina, A.G., Panova, A.S., Marygin, R.A., Staroverov, D.B., Bilan, D.S., et al. (2018). SypHer3s: a genetically encoded fluorescent ratiometric probe with enhanced brightness and an improved dynamic range. Chem. Commun. 54: 2898-2901.

Ezerina, D., Morgan, B., and Dick, T.P. (2014). Imaging dynamic redox processes with genetically encoded probes. J. Mol. Cell. Cardiol. 73: 43-9.

Farrell, J.A., Wang, Y., Riesenfeld, S.J., Shekhar, K., Regev, A., and Schier, A.F. (2018). Single-cell reconstruction of developmental trajectories during zebrafish embryogenesis. Science 360 , https://doi.org/10.1126/science.aar3131.

Ferreira, F., Luxardi, G., Reid, B., and Zhao, M. (2016). Early bioelectric activities mediate redox-modulated regeneration. Development 143: 4582-4594.

Ferreira, F., Raghunathan, V., Luxardi, G., Zhu, K., and Zhao, M. (2018). Early redox activities modulate Xenopus tail regeneration. Nat. Commun. 9: 4296.

Finkel, T. (2011). Signal transduction by reactive oxygen species. JCB (J. Cell Biol.) 194: 7-15. 
Flinck, M., Kramer, S.H., and Pedersen, S.F. (2018). Roles of pH in control of cell proliferation. Acta Physiol. 223: e13068.

Froland Steindal, I.A., and Whitmore, D. (2019). Circadian clocks in fish-what have we learned so far? Biology, 8, https://doi.org/10. 3390/biology8010017.

Funato, Y., Michiue, T., Asashima, M., and Miki, H. (2006). The thioredoxin-related redox-regulating protein nucleoredoxin inhibits Wnt- $\beta$-catenin signalling through dishevelled. Nat. Cell Biol. 8: 501-8.

Gauron, C., Meda, F., Dupont, E., Albadri, S., Quenech'du, N., Ipendey, E., Volovitch, M., Del Bene, F., Joliot, A., Rampon, C., and Vriz, S. (2016). Hydrogen peroxide $\left(\mathrm{H}_{2} \mathrm{O}_{2}\right)$ controls axon pathfinding during zebrafish development. Dev. Biol. 414: 133-41.

Gauron, C., Rampon, C., Bouzaffour, M., Ipendey, E., Teillon, J., Volovitch, M., and Vriz, S. (2013). Sustained production of ROS triggers compensatory proliferation and is required for regeneration to proceed. Sci. Rep. 3: 2084.

Glorieux, C. and Calderon, P.B. (2017). Catalase, a remarkable enzyme: targeting the oldest antioxidant enzyme to find a new cancer treatment approach. Biol. Chem. 398: 1095-1108.

Grunwald, D.J. and Eisen, J.S. (2002). Headwaters of the zebrafish -emergence of a new model vertebrate. Nat. Rev. Genet. 3: 717-24.

Gut, P., Reischauer, S., Stainier, D.Y.R., and Arnaout, R. (2017). Little fish, big data: zebrafish as a model for cardiovascular and metabolic disease. Physiol. Rev. 97: 889-938.

Gutscher, M., Pauleau, A.L., Marty, L., Brach, T., Wabnitz, G.H., Samstag, Y., Meyer, A.J., and Dick, T.P. (2008). Real-time imaging of the intracellular glutathione redox potential. Nat. Methods 5: 553-9.

Gutscher, M., Sobotta, M.C., Wabnitz, G.H., Ballikaya, S., Meyer, A.J., Samstag, Y., and Dick, T.P. (2009). Proximity-based protein thiol oxidation by $\mathrm{H}_{2} \mathrm{O}_{2}$-scavenging peroxidases. J. Biol. Chem. 284: 31532-40.

Han, P., Zhou, X.H., Chang, N., Xiao, C.L., Yan, S., Ren, H., Yang, X.Z., Zhang, M.L., Wu, Q., Tang, B., et al. (2014). Hydrogen peroxide primes heart regeneration with a derepression mechanism. Cell Res. 24: 1091-107.

Hanschmann, E.M., Godoy, J.R., Berndt, C., Hudemann, C., and Lillig, C.H. (2013). Thioredoxins, glutaredoxins, and peroxiredoxins-molecular mechanisms and health significance: from cofactors to antioxidants to redox signaling. Antioxidants Redox Signal. 19: 1539-605.

Hasegawa, T., Hall, C.J., Crosier, P.S., Abe, G., Kawakami, K., Kudo, A., and Kawakami, A. (2017). Transient inflammatory response mediated by interleukin- $1 \beta$ is required for proper regeneration in zebrafish fin fold. eLife 6, https://doi.org/10.7554/elife.22716.

Hernandez-Garcia, D., Wood, C.D., Castro-Obregon, S., and Covarrubias, L. (2010). Reactive oxygen species: a radical role in development? Free Radic. Biol. Med. 49: 130-43.

Hervera, A., Santos, C.X., De Virgiliis, F., Shah, A.M., and Di Giovanni, S. (2019). Paracrine mechanisms of redox signalling for postmitotic cell and tissue regeneration. Trends Cell Biol. 29: 514-530.

Hinton, A., Bond, S., and Forgac, M. (2009). V-ATPase functions in normal and disease processes. Pflüger's Archiv - European Journal of Physiology 457: 589-98.

Holmstrom, K.M. and Finkel, T. (2014). Cellular mechanisms and physiological consequences of redox-dependent signalling. Nat. Rev. Mol. Cell Biol. 15: 411-21.
Hunter, M.V., Willoughby, P.M., Bruce, A.E.E., and Fernandez Gonzalez, R. (2018). Oxidative stress orchestrates cell polarity to promote embryonic wound healing. Dev. Cell 47: 377-387 e4.

lismaa, S.E., Kaidonis, X., Nicks, A.M., Bogush, N., Kikuchi, K., Naqvi, N., Harvey, R.P., Husain, A., and Graham, R.M. (2018). Comparative regenerative mechanisms across different mammalian tissues. npj Regenerative Medicine 3: 6.

Jelcic, M., Enyedi, B., Xavier, J.B., and Niethammer, P. (2017). Imagebased measurement of $\mathrm{H}_{2} \mathrm{O}_{2}$ reaction-diffusion in wounded zebrafish larvae. Biophys. J. 112: 2011-2018.

Jopling, C., Sleep, E., Raya, M., Marti, M., Raya, A., and Izpisua Belmonte, J.C. (2010). Zebrafish heart regeneration occurs by cardiomyocyte dedifferentiation and proliferation. Nature 464: 606-9.

Kang, J., Hu, J., Karra, R., Dickson, A.L., Tornini, V.A., Nachtrab, G., Gemberling, M., Goldman, J.A., Black, B.L., and Poss, K.D. (2016). Modulation of tissue repair by regeneration enhancer elements. Nature 532: 201-6.

Kawakami, A., Fukazawa, T., and Takeda, H. (2004). Early fin primordia of zebrafish larvae regenerate by a similar growth control mechanism with adult regeneration. Dev. Dynam. 231: 693-9.

Keller, P.J., Schmidt, A.D., Wittbrodt, J., and Stelzer, E.H. (2008). Reconstruction of zebrafish early embryonic development by scanned light sheet microscopy. Science 322: 1065-9.

Kikuchi, K., Holdway, J.E., Werdich, A.A., Anderson, R.M., Fang, Y., Egnaczyk, G.F., Evans, T., Macrae, C.A., Stainier, D.Y., and Poss, K.D. (2010). Primary contribution to zebrafish heart regeneration by gata $4^{+}$cardiomyocytes. Nature 464: 601-5.

Kil, I.S., Lee, S.K., Ryu, K.W., Woo, H.A., Hu, M.C., Bae, S.H., and Rhee, S.G. (2012). Feedback control of adrenal steroidogenesis via $\mathrm{H}_{2} \mathrm{O}_{2}$-dependent, reversible inactivation of peroxiredoxin III in mitochondria. Mol. Cell 46: 584-94.

Kimmel, C.B., Ballard, W.W., Kimmel, S.R., Ullmann, B., and Schilling, T.F. (1995). Stages of embryonic development of the zebrafish. Dev. Dynam. 203: 253-310.

Kita, E.M., Scott, E.K., and Goodhill, G.J. (2015). Topographic wiring of the retinotectal connection in zebrafish. Developmental Neurobiology 75: 542-56.

Kizil, C., Kuchler, B., Yan, J.J., Ozhan, G., Moro, E., Argenton, F., Brand, M., Weidinger, G., and Antos, C.L. (2014). Simplet/Fam53b is required for Wnt signal transduction by regulating $\beta$-catenin nuclear localization. Development 141: 3529-39.

Kizil, C., Otto, G.W., Geisler, R., Nusslein-Volhard, C., and Antos, C.L. (2009). Simplet controls cell proliferation and gene transcription during zebrafish caudal fin regeneration. Dev. Biol. 325: 329-40.

Klyubin, I.V., Kirpichnikova, K.M., and Gamaley, I.A. (1996). Hydrogen peroxide-induced chemotaxis of mouse peritoneal neutrophils. Eur. J. Cell Biol. 70: 347-51.

Kornberg, T.B. (2014). Cytonemes and the dispersion of morphogens. Wiley Interdisciplinary Reviews-Developmental Biology 3: 445-63.

Kostyuk, A.I., Demidovich, A.D., Kotova, D.A., Belousov, V.V., and Bilan, D.S. (2019). Circularly permuted fluorescent protein-based indicators: history, principles, and classification. Int. J. Mol. Sci. 20, https://doi.org/10.3390/ijms20174200.

Lai, J.K.H., Gagalova, K.K., Kuenne, C., El-Brolosy, M.A., and Stainier, D.Y.R. (2019). Induction of interferon-stimulated genes and cellular stress pathways by morpholinos in zebrafish. Dev. Biol. 454: 21-28. 
Lam, P.Y. and Peterson, R.T. (2019). Developing zebrafish disease models for in vivo small molecule screens. Curr. Opin. Chem. Biol. 50: 37-44.

Lebert, D., Squirrell, J.M., Freisinger, C., Rindy, J., Golenberg, N., Frecentese, G., Gibson, A., Eliceiri, K.W., and Huttenlocher, A. (2018). Damage-induced reactive oxygen species regulate vimentin and dynamic collagen-based projections to mediate wound repair. eLife 7, https://doi.org/10.7554/elife.30703.

Leichert, L.I., Gehrke, F., Gudiseva, H.V., Blackwell, T., Ilbert, M., Walker, A.K., Strahler, J.R., Andrews, P.C., and Jakob, U. (2008). Quantifying changes in the thiol redox proteome upon oxidative stress in vivo. Proc. Natl. Acad. Sci. U.S.A. 105: 8197-202.

Lennicke, C., Rahn, J., Heimer, N., Lichtenfels, R., Wessjohann, L.A., and Seliger, B. (2016). Redox proteomics: methods for the identification and enrichment of redox-modified proteins and their applications. Proteomics 16: 197-213.

Lin, L.Y., Horng, J.L., Kunkel, J.G., and Hwang, P.P. (2006). Proton pump-rich cell secretes acid in skin of zebrafish larvae. Am. J. Physiol. Cell Physiol. 290: C371-8.

Liu, K., Petree, C., Requena, T., Varshney, P., and Varshney, G.K. (2019). Expanding the CRISPR toolbox in zebrafish for studying development and disease. Frontiers in Cell and Developmental Biology 7: 13 .

Llufrio, E.M., Wang, L., Naser, F.J., and Patti, G.J. (2018). Sorting cells alters their redox state and cellular metabolome. Redox Biology 16: 381-387.

Lohr, H. and Hammerschmidt, M. (2011). Zebrafish in endocrine systems: recent advances and implications for human disease. Annu. Rev. Physiol. 73: 183-211.

Love, N.R., Chen, Y., Ishibashi, S., Kritsiligkou, P., Lea, R., Koh, Y., Gallop, J.L., Dorey, K., and Amaya, E. (2013). Amputation-induced reactive oxygen species are required for successful Xenopus tadpole tail regeneration. Nat. Cell Biol. 15: 222-8.

Lu, J., Liu, K.C., Schulz, N., Karampelias, C., Charbord, J., Hilding, A., Rautio, L., Bertolino, P., Ostenson, C.G., Brismar, K., et al. (2016). IGFBP1 increases $\beta$-cell regeneration by promoting alpha- to beta-cell transdifferentiation. EMBO J. 35: 2026-44.

Lush, M.E., Diaz, D.C., Koenecke, N., Baek, S., Boldt, H., St Peter, M.K., Gaitan-Escudero, T., Romero-Carvajal, A., Busch-Nentwich, E.M., Perera, A.G., et al. (2019). scRNA-Seq reveals distinct stem cell populations that drive hair cell regeneration after loss of Fgf and Notch signaling. eLlife 8, https://doi.org/10.7554/elife.44431.

Mahmoud, A.I., O'meara, C.C., Gemberling, M., Zhao, L., Bryant, D.M., Zheng, R., Gannon, J.B., Cai, L., Choi, W.Y., Egnaczyk, G.F., et al. (2015). Nerves regulate cardiomyocyte proliferation and heart regeneration. Dev. Cell 34: 387-99.

Margis, R., Dunand, C., Teixeira, F.K., and Margis-Pinheiro, M. (2008). Glutathione peroxidase family - an evolutionary overview. FEBS J. 275: 3959-70.

Marques, I.J., Lupi, E., and Mercader, N. (2019). Model systems for regeneration: zebrafish. Development, p. 146.

Martins, R.R., Ellis, P.S., Macdonald, R.B., Richardson, R.J., and Henriques, C.M. (2019). Resident immunity in tissue repair and maintenance: the zebrafish model coming of age. Frontiers in Cell and Developmental Biology 7: 12 .

Mateus, R., Pereira, T., Sousa, S., De Lima, J.E., Pascoal, S., Saude, L., and Jacinto, A. (2012). In vivo cell and tissue dynamics underlying zebrafish fin fold regeneration. PloS One 7: e51766.

Matlashov, M.E., Bogdanova, Y.A., Ermakova, G.V., Mishina, N.M., Ermakova, Y.G., Nikitin, E.S., Balaban, P.M., Okabe, S.,
Lukyanov, S., Enikolopov, G., et al. (2015). Fluorescent ratiometric $\mathrm{pH}$ indicator SypHer2: applications in neuroscience and regenerative biology. Biochim. Biophys. Acta 1850: 2318-28.

Meda, F., Gauron, C., Rampon, C., Teillon, J., Volovitch, M., and Vriz, S. (2016). Nerves control redox levels in mature tissues through schwann cells and hedgehog signaling. Antioxidants Redox Signal. 24: 299-311.

Meda, F., Rampon, C., Dupont, E., Gauron, C., Mourton, A., Queguiner, I., Thauvin, M., Volovitch, M., Joliot, A., and Vriz, S. (2018). Nerves, $\mathrm{H}_{2} \mathrm{O}_{2}$ and Shh: three players in the game of regeneration. Semin. Cell Dev. Biol. 80: 65-73.

Menger, K.E., James, A.M., Cocheme, H.M., Harbour, M.E., Chouchani, E.T., Ding, S., Fearnley, I.M., Partridge, L., and Murphy, M.P. (2015). Fasting, but not aging, dramatically alters the redox status of cysteine residues on proteins in Drosophila melanogaster. Cell Rep. 13: 1285.

Mokalled, M.H. and Poss, K.D. (2018). A regeneration toolkit. Dev. Cell 47: 267-280.

Monteiro, J., Aires, R., Becker, J.D., Jacinto, A., Certal, A.C., and RodriguezLeon, J. (2014). V-ATPase proton pumping activity is required for adult zebrafish appendage regeneration. PloS One 9: e92594.

Morgan, B., Van Laer, K., Owusu, T.N., Ezerina, D., Pastor-Flores, D., Amponsah, P.S., Tursch, A., and Dick, T.P. (2016). Real-time monitoring of basal $\mathrm{H}_{2} \mathrm{O}_{2}$ levels with peroxiredoxin-based probes. Nat. Chem. Biol. 12: 437-43.

Moro, E., Vettori, A., Porazzi, P., Schiavone, M., Rampazzo, E., Casari, A., Ek, O., Facchinello, N., Astone, M., Zancan, I., et al. (2013). Generation and application of signaling pathway reporter lines in zebrafish. Mol. Genet. Genom. 288: 231-42.

Nachtrab, G., Kikuchi, K., Tornini, V.A., and Poss, K.D. (2013). Transcriptional components of anteroposterior positional information during zebrafish fin regeneration. Development 140: 3754-64.

Niethammer, P. (2016). The early wound signals. Curr. Opin. Genet. Dev. 40: 17-22.

Niethammer, P., Grabher, C., Look, A.T., and Mitchison, T.J. (2009). A tissue-scale gradient of hydrogen peroxide mediates rapid wound detection in zebrafish. Nature 459: 996-9.

O'donnell, K.C., Vargas, M.E., and Sagasti, A. (2013). WIdS and PGC1alpha regulate mitochondrial transport and oxidation state after axonal injury. J. Neurosci. 33: 14778-90.

Olguin-Albuerne, M., and Moran, J. (2018). Redox signaling mechanisms in nervous system development. Antioxidants Redox Signal. 28: 1603-1625.

Orban, L., Sreenivasan, R., and Olsson, P.E. (2009). Long and winding roads: testis differentiation in zebrafish. Mol. Cell. Endocrinol. 312: 35-41.

Orger, M.B. and De Polavieja, G.G. (2017). Zebrafish behavior: opportunities and challenges. Annu. Rev. Neurosci. 40: 125-147.

Pak, V.V., Ezerina, D., Lyublinskaya, O.G., Pedre, B., Tyurin-Kuzmin, P.A., Mishina, N.M., Thauvin, M., Young, D., Wahni, K., Martinez Gache, S.A., et al. (2020). Ultrasensitive genetically encoded indicator for hydrogen peroxide identifies roles for the oxidant in cell migration and mitochondrial function. Cell Metabol. 31: 642-653 e6.

Panday, A., Sahoo, M.K., Osorio, D., and Batra, S. (2015). NADPH oxidases: an overview from structure to innate immunityassociated pathologies. Cell. Mol. Immunol. 12: 5-23. 
Panieri, E., Millia, C., and Santoro, M.M. (2017). Real-time quantification of subcellular $\mathrm{H}_{2} \mathrm{O}_{2}$ and glutathione redox potential in living cardiovascular tissues. Free Radic. Biol. Med. 109: 189-200.

Panieri, E. and Santoro, M.M. (2017). Data on metabolic-dependent antioxidant response in the cardiovascular tissues of living zebrafish under stress conditions. Data in Brief 12: 427-432.

Pare, J.F., Martyniuk, C.J., and Levin, M. (2017). Bioelectric regulation of innate immune system function in regenerating and intact Xenopus laevis. Regen. Med. 2: 15.

Pase, L., Layton, J.E., Wittmann, C., Ellett, F., Nowell, C.J., ReyesAldasoro, C.C., Varma, S., Rogers, K.L., Hall, C.J., Keightley, M.C., et al. (2012). Neutrophil-delivered myeloperoxidase dampens the hydrogen peroxide burst after tissue wounding in zebrafish. Curr. Biol. 22: 1818-24.

Pastor-Flores, D., Talwar, D., Pedre, B., and Dick, T.P. (2020). Realtime monitoring of peroxiredoxin oligomerization dynamics in living cells. Proc. Natl. Acad. Sci. U.S.A. 117: 16313-16323.

Patton, E.E. and Zon, L.I. (2001). The art and design of genetic screens: zebrafish. Nat. Rev. Genet. 2: 956-66.

Perlin, J.R., Robertson, A.L., and Zon, L.I. (2017). Efforts to enhance blood stem cell engraftment: recent insights from zebrafish hematopoiesis. J. Exp. Med. 214: 2817-2827.

Petrie, T.A., Strand, N.S., Yang, C.T., Rabinowitz, J.S., and Moon, R.T. (2014). Macrophages modulate adult zebrafish tail fin regeneration. Development 141: 2581-91.

Poburko, D., Santo-Domingo, J., and Demaurex, N. (2011). Dynamic regulation of the mitochondrial proton gradient during cytosolic calcium elevations. J. Biol. Chem. 286: 11672-84.

Pogoda, H.M. and Hammerschmidt, M. (2009). How to make a teleost adenohypophysis: molecular pathways of pituitary development in zebrafish. Mol. Cell. Endocrinol. 312: 2-13.

Prozorovski, T., Schneider, R., Berndt, C., Hartung, H.P., and Aktas, 0. (2015). Redox-regulated fate of neural stem progenitor cells. Biochim. Biophys. Acta 1850: 1543-54.

Putker, M. and O'neill, J.S. (2016). Reciprocal control of the circadian clock and cellular redox state - a critical appraisal. Mol. Cell. 39: 6-19.

Rhee, S.G. and Kil, I.S. (2016). Mitochondrial $\mathrm{H}_{2} \mathrm{O}_{2}$ signaling is controlled by the concerted action of peroxiredoxin III and sulfiredoxin: linking mitochondrial function to circadian rhythm. Free Radic. Biol. Med. 100: 73-80.

Rieger, S. and Sagasti, A. (2011). Hydrogen peroxide promotes injuryinduced peripheral sensory axon regeneration in the zebrafish skin. PLoS Biol. 9: e1000621.

Ristow, M., Zarse, K., Oberbach, A., Kloting, N., Birringer, M., Kiehntopf, M., Stumvoll, M., Kahn, C.R., and Bluher, M. (2009). Antioxidants prevent health-promoting effects of physical exercise in humans. Proc. Natl. Acad. Sci. U.S.A. 106: 8665-70.

Roehl, H.H. (2018). Linking wound response and inflammation to regeneration in the zebrafish larval fin. Int. J. Dev. Biol. 62: 473-477.

Romero, M.M.G., Mccathie, G., Jankun, P., and Roehl, H.H. (2018). Damage-induced reactive oxygen species enable zebrafish tail regeneration by repositioning of Hedgehog expressing cells. Nat. Commun. 9: 4010.

Rossi, A., Kontarakis, Z., Gerri, C., Nolte, H., Holper, S., Kruger, M., and Stainier, D.Y. (2015). Genetic compensation induced by deleterious mutations but not gene knockdowns. Nature 524: 230-3.
Schieber, M. and Chandel, N.S. (2014). ROS function in redox signaling and oxidative stress. Curr. Biol. 24: R453-62.

Schier, A.F. and Talbot, W.S. (2005). Molecular genetics of axis formation in zebrafish. Annu. Rev. Genet. 39: 561-613.

Schmidt, R., Strahle, U., and Scholpp, S. (2013). Neurogenesis in zebrafish - from embryo to adult. Neural Dev. 8: 3.

Schulte-Merker, S. and Stainier, D.Y. (2014). Out with the old, in with the new: reassessing morpholino knockdowns in light of genome editing technology. Development 141: 3103-4.

Schwarzlander, M., Dick, T.P., Meyer, A.J., and Morgan, B. (2016). Dissecting redox biology using fluorescent protein sensors. Antioxidants Redox Signal. 24: 680-712.

Schwarzlander, M., Fricker, M.D., Muller, C., Marty, L., Brach, T., Novak, J., Sweetlove, L.J., Hell, R., and Meyer, A.J. (2008). Confocal imaging of glutathione redox potential in living plant cells. J. Microsc. 231: 299-316.

Sehring, I.M. and Weidinger, G. (2020). Recent advancements in understanding fin regeneration in zebrafish, Wiley Interdiscipl Rev\-Develop Biolo.9: e367.

Seiler, C., Davuluri, G., Abrams, J., Byfield, F.J., Janmey, P.A., and Pack, M. (2012). Smooth muscle tension induces invasive remodeling of the zebrafish intestine. PLoS Biol. 10: e1001386.

Sies, H., Berndt, C., and Jones, D.P. (2017). Oxidative stress. Annu. Rev. Biochem. 86: 715-748.

Sies, H. and Jones, D.P. (2020). Reactive oxygen species (ROS) as pleiotropic physiological signalling agents. Nat. Rev. Mol. Cell Biol. 21: 363-383.

Simoes, M.G., Bensimon-Brito, A., Fonseca, M., Farinho, A., Valerio, F., Sousa, S., Afonso, N., Kumar, A., and Jacinto, A. (2014). Denervation impairs regeneration of amputated zebrafish fins. BMC Dev. Biol. 14: 49.

Sladitschek, H.L., Fiuza, U.M., Pavlinic, D., Benes, V., Hufnagel, L., and Neveu, P.A. (2020). MorphoSeq: full single-cell transcriptome dynamics up to gastrulation in a chordate. Cell 181: 922-935 e21.

Solnica-Krezel, L. and Sepich, D.S. (2012). Gastrulation: making and shaping germ layers. Annu. Rev. Cell Dev. Biol. 28: 687-717.

Sorce, S., Stocker, R., Seredenina, T., Holmdahl, R., Aguzzi, A., Chio, A., Depaulis, A., Heitz, F., Olofsson, P., Olsson, T., et al. (2017). NADPH oxidases as drug targets and biomarkers in neurodegenerative diseases: what is the evidence? Free Radic. Biol. Med. 112: 387-396.

Spanjaard, B., Hu, B., Mitic, N., Olivares-Chauvet, P., Janjuha, S. Ninov, N., and Junker, J.P. (2018). Simultaneous lineage tracing and cell-type identification using CRISPR-Cas9-induced genetic scars. Nat. Biotechnol. 36: 469-473.

Stainier, D.Y.R., Raz, E., Lawson, N.D., Ekker, S.C., Burdine, R.D., Eisen, J.S., Ingham, P.W., Schulte-Merker, S., Yelon, D., Weinstein, B.M., et al. (2017). Guidelines for morpholino use in zebrafish. PLoS Genet. 13: e1007000.

Stocker, S., Maurer, M., Ruppert, T., and Dick, T.P. (2018a). A role for 2-Cys peroxiredoxins in facilitating cytosolic protein thiol oxidation. Nat. Chem. Biol. 14: 148-155.

Stocker, S., Van Laer, K., Mijuskovic, A., and Dick, T.P. (2018b). The conundrum of hydrogen peroxide signaling and the emerging role of peroxiredoxins as redox relay hubs. Antioxidants Redox Signal. 28: 558-573.

Stoddard, M., Huang, C., Enyedi, B., and Niethammer, P. (2019). Live imaging of leukocyte recruitment in a zebrafish model of chemical liver injury. Sci. Rep. 9: 28. 
Sutcu, H.H. and Ricchetti, M. (2018). Loss of heterogeneity, quiescence, and differentiation in muscle stem cells. Stem Cell Invest. 5: 9 .

Topf, U., Suppanz, I., Samluk, L., Wrobel, L., Boser, A., Sakowska, P., Knapp, B., Pietrzyk, M.K., Chacinska, A., and Warscheid, B. (2018). Quantitative proteomics identifies redox switches for global translation modulation by mitochondrially produced reactive oxygen species. Nat. Commun. 9: 324.

Trinh Le, A. and Fraser, S.E. (2013). Enhancer and gene traps for molecular imaging and genetic analysis in zebrafish. Dev. Growth Differ. 55: 434-45.

Veldman, M.B., Bemben, M.A., Thompson, R.C., and Goldman, D. (2007). Gene expression analysis of zebrafish retinal ganglion cells during optic nerve regeneration identifies KLF6a and KLF7a as important regulators of axon regeneration. Dev. Biol. 312: 596-612.

Wagner, D.E., Weinreb, C., Collins, Z.M., Briggs, J.A., Megason, S.G., and Klein, A.M. (2018). Single-cell mapping of gene expression landscapes and lineage in the zebrafish embryo. Science 360: 981-987.

Wang, G., Cao, L., Liu, X., Sieracki, N.A., Di, A., Wen, X., Chen, Y., Taylor, S., Huang, X., Tiruppathi, C., et al. (2016). Oxidant sensing by TRPM2 inhibits neutrophil migration and mitigates inflammation. Dev. Cell 38: 453-62.

Weaver, C.J., Terzi, A., Roeder, H., Gurol, T., Deng, Q., Leung, Y.F., and Suter, D.M. (2018). nox2/cybb deficiency affects zebrafish retinotectal connectivity. J. Neurosci. 38: 5854-5871.

Weger, B.D., Weger, M., Gorling, B., Schink, A., Gobet, C., Keime, C., Poschet, G., Jost, B., Krone, N., Hell, R., et al. (2016). Extensive regulation of diurnal transcription and metabolism by glucocorticoids. PLoS Genet. 12: e1006512.

Weger, M., Weger, B.D., Diotel, N., Rastegar, S., Hirota, T., Kay, S.A., Strahle, U., and Dickmeis, T. (2013). Real-time in vivo monitoring of circadian E-box enhancer activity: a robust and sensitive zebrafish reporter line for developmental, chemical and neural biology of the circadian clock. Dev. Biol. 380: 259-73.

Weger, M., Weger, B.D., Gorling, B., Poschet, G., Yildiz, M., Hell, R., Luy, B., Akcay, T., Guran, T., Dickmeis, T., et al. (2018). Glucocorticoid deficiency causes transcriptional and posttranscriptional reprogramming of glutamine metabolism. EBioMedicine 36: 376-389.

Wilson, C., Munoz-Palma, E., and Gonzalez-Billault, C. (2018). From birth to death: a role for reactive oxygen species in neuronal development. Semin. Cell Dev. Biol. 80: 43-49.

Winterbourn, C.C. (2014). The challenges of using fluorescent probes to detect and quantify specific reactive oxygen species in living cells. Biochim. Biophys. Acta 1840: 730-8.

Winterbourn, C.C. (2020). Biological chemistry of superoxide radicals. ChemTexts 6: 7 .
Wong, H.S., Dighe, P.A., Mezera, V., Monternier, P.A., and Brand, M.D. (2017). Production of superoxide and hydrogen peroxide from specific mitochondrial sites under different bioenergetic conditions. J. Biol. Chem. 292: 16804-16809.

Wragg, J.W., Roos, L., Vucenovic, D., Cvetesic, N., Lenhard, B., and Muller, F. (2020). Embryonic tissue differentiation is characterized by transitions in cell cycle dynamic-associated core promoter regulation. Nucleic Acids Res., https://doi.org/10. 5040/9781509927265.

Wu, W., Hale, A.J., Lemeer, S., and Den Hertog, J. (2017). Differential oxidation of protein-tyrosine phosphatases during zebrafish caudal fin regeneration. Sci. Rep. 7: 8460.

Xiao, H., Jedrychowski, M.P., Schweppe, D.K., Huttlin, E.L., Yu, Q., Heppner, D.E., Li, J., Long, J., Mills, E.L., Szpyt, J., et al. (2020). A quantitative tissue-specific landscape of protein redox regulation during aging. Cell 180: 968-983 e24.

Yabe, T. and Takada, S. (2016). Molecular mechanism for cyclic generation of somites: lessons from mice and zebrafish. Dev. Growth Differ. 58: 31-42.

Yang, K. and Kang, J. (2019). Tissue regeneration enhancer elements: a way to unlock endogenous healing power. Dev. Dynam. 248: 34-42.

Yoo, S.K., Freisinger, C.M., Lebert, D.C., and Huttenlocher, A. (2012). Early redox, Src family kinase, and calcium signaling integrate wound responses and tissue regeneration in zebrafish. JCB (J. Cell Biol.) 199: 225-34.

Yoo, S.K., Starnes, T.W., Deng, Q., and Huttenlocher, A. (2011). Lyn is a redox sensor that mediates leukocyte wound attraction in vivo. Nature 480: 109-12.

Zambusi, A. and Ninkovic, J. (2020). Regeneration of the central nervous system-principles from brain regeneration in adult zebrafish. World J. Stem Cell. 12: 8-24.

Zhang, D.D. and Hannink, M. (2003). Distinct cysteine residues in Keap1 are required for Keap1-dependent ubiquitination of Nrf2 and for stabilization of Nrf2 by chemopreventive agents and oxidative stress. Mol. Cell Biol. 23: 8137-51.

Zielonka, J. and Kalyanaraman, B. (2018). Small-molecule luminescent probes for the detection of cellular oxidizing and nitrating species. Free Radic. Biol. Med. 128: 3-22.

Zinski, J., Tajer, B., and Mullins, M.C. (2018). TGF- $\beta$ family signaling in early vertebrate development. Cold Spring Harbor Perspectives in Biology 10, https://doi.org/10.1101/ cshperspect.a033274.

Zoidl, G., Bruzzone, R., Weickert, S., Kremer, M., Zoidl, C., Mitropoulou, G., Srinivas, M., Spray, D.C., and Dermietzel, R. (2004). Molecular cloning and functional expression of $\mathrm{zfCx} 52.6$ : a novel connexin with hemichannel-forming properties expressed in horizontal cells of the zebrafish retina. J. Biol. Chem. 279: 2913-21. 